\title{
Active Power Filter DC Bus Voltage Piecewise Reaching Law Variable Structure Control
}

\author{
Baolian Liu, Zujun Ding, Huanyu Zhao, and Defei Jin \\ Department of Electronic and Electrical Engineering, Huaiyin Institute of Technology, Huaian, Jiangsu 223003, China \\ Correspondence should be addressed to Zujun Ding; dzj_king@263.net
}

Received 21 July 2014; Accepted 14 August 2014; Published 2 September 2014

Academic Editor: Zhiguang Feng

Copyright (C) 2014 Baolian Liu et al. This is an open access article distributed under the Creative Commons Attribution License, which permits unrestricted use, distribution, and reproduction in any medium, provided the original work is properly cited.

The DC bus voltage stability control is one key technology to ensure that Active Power Filter (APF) operates stably. The external disturbances such as power grid and load fluctuation and the system parameters changing may affect the stability of APF DC bus voltage and the normal operation of APF. The mathematical model of DC bus voltage is established according to power balance principle and a DC bus voltage piecewise reaching law variable structure control algorithm is proposed to solve the above problem, and the design method is given. The simulation and experiment results proved that the proposed variable structure control algorithm can eliminate the chattering problem existing in traditional variable structure control effectively, is insensitive to system disturbance, and has good robustness and fast dynamic response speed and stable DC bus voltage with small fluctuation. The above advantages ensure the compensation effect of APF.

\section{Introduction}

Recently, power electronic technology has been widely developed and applied. A lot of harmonic and reactive currents inject into the power grid as the power electronic devices and nonlinear loads used in industry. This can cause partial parallel resonance and series resonance in electric power system, power grid, and electrical equipment problems $[1,2]$. APF is a new power electronic device designed for suppressing harmonic current. It can compensate each harmonic current and reactive power [3].

The APF power circuit usually consists of voltage source inverter and the drive circuit. It is very important to maintain the stability of DC side capacitor voltage for the whole control system. Low DC side capacitor voltage will reduce the compensation precision of APF. Conversely, high DC side capacitor voltage will make the interference harmonic current of APF increase. Therefore, controlling the DC side voltage of inverter and maintaining it stable have important significance for the APF harmonic current compensation effect [4-8].

However, when the device actually operate, the power consumption of switching devices, loading and unloading nonlinear load process, energy fluctuation in the DC side caused by AC side voltage fluctuation, and other factors will make the power grid and DC side capacitor exchange active power. This will lead to bus voltage fluctuation [9]. Nonideal power source voltage will lead to the rising of DC side voltage, influence the compensation performance, and even damage the security of the system [10]. The DC side voltage fluctuation is even larger when the harmonic current and reactive power are compensated meanwhile. This will seriously affect the compensation accuracy [11].

Generally, the normal APF DC bus voltage control methods are PI control and fuzzy control. Because of having strong robustness and less depending on the accurate model, the fuzzy control has attracted extensive application [10, 11]. In [12], the authors proposed a fuzzy controller to control the DC side voltage and illustrated the fuzzy control rules in detail according to the error and change rate of error. But the control rules can not be adjusted and the robustness is limited. In [13], the fuzzy and PI controller were combined, and the fuzzy controller was used to automatically adjust the PI controller parameters. The stable and dynamic performance were improved to a certain extent. But the control effect is 


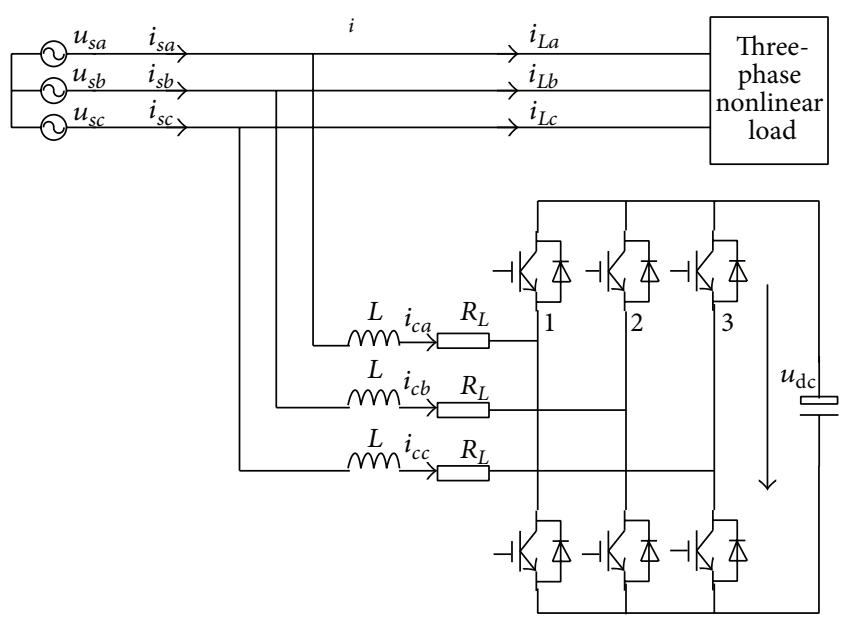

FIGURE 1: Structure diagram of APF converter main circuit.

normally seen from the experiment results. In [14], the fuzzy internal model controller was used to control the DC bus voltage, but the controller structure is complex.

Variable structure control has the characteristics of low dependence on mathematical model of the controlled object, insensitive to parameter variations and external disturbances $[15,16]$. Yufeng et al. [17] combined adaptive control and variable structure control to suppress the harmonics and improve power factor [18]. And a DC bus voltage variable structure controller is designed in this paper based on modeling the APF DC bus voltage. Aimed at the chattering problem of traditional variable structure control reaching law, a piecewise reaching law is presented for variable structure controller in this paper to optimize the control strategy. Finally, the simulation and experiment results are given.

\section{The Analysis to Model APF DC Bus Voltage Control}

Figure 1 gives the topology structure of three-phase shunt APF. The main part is a two-level converter, which connect with power grid through filter inductor, where $R_{L}$ is the resistor of the filter inductor.

In the converter, the 1st, 2nd, and 3rd bridge are used to produce compensation current $i_{c a}, i_{c b}, i_{c c}$ of phase A, B, and $\mathrm{C}$, respectively. The corresponding instruction current $i_{c a}^{*}$, $i_{c b}^{*}, i_{c c}^{*}$ produced by arithmetic circuit. In ideal condition, the compensation current $i_{c a}, i_{c b}, i_{c c}$ which is produced according to instruction current will offset the harmonic current and fundamental reactive current. Thus, the power grid current is sine wave and three-phase symmetrical.

In [19], the power consumption of a resistor which paralleled with DC bus was used to replace the whole APF power consumption, rather than the real power consumption of the filter inductor and power electronic devices. The paper did not consider the change of APF compensation current caused by power grid voltage and load disturbance, which will lead to the change of power consumption. The power consumption of power electronic devices was considered in [20], but except the on state loss and the filter inductor copper loss.

Assume that the fundamental active current increment of phase A caused by DC bus voltage fluctuation is $\Delta i_{a 1}$. Let

$$
\begin{aligned}
u_{s a} & =\sqrt{2} U \sin (\omega t), \\
\Delta i_{s a 1} & =\sqrt{2} \Delta I_{1} \sin (\omega t) ;
\end{aligned}
$$

then the instantaneous power change of phase A caused by the fluctuation of DC bus voltage is

$$
p_{a}=2 \Delta I_{1} U \sin ^{2}(\omega t)
$$

The total instantaneous power change of the whole system caused by the fluctuation of DC bus voltage is

$$
p_{\text {out }}=p_{a}+p_{b}+p_{c}
$$

Assume that the three-phase voltage and current are symmetric; thus the total instantaneous power change of the whole system caused by the fluctuation of DC bus voltage can be expressed:

$$
p_{\text {out }}=3 U \Delta I_{1} \text {. }
$$

The instantaneous power of APF absorbed from power grid is mainly stored in the bus capacitor to maintain the bus voltage and the power consumption of equal resistor of filter inductor and power electronic devices.

Xie et al. [21] denote that (1) the on state loss is proportional to forward voltage drop and conduction current, while the forward voltage drop will increase along with the conduction current increasing; (2) the switching loss increases along with the DC bus voltage raise.

For the conclusion (1), the on state loss of switching devices can be expressed by

$$
p_{\mathrm{on}}=R_{\mathrm{on}}\left(i_{c a}^{2}+i_{c b}^{2}+i_{c c}^{2}\right)
$$

where $i_{c k}(k=a, b, c)$ are the APF compensation currents. As the three-phase load is symmetric, the $i_{c k}$ are symmetric, so there is

$$
p_{\text {on }}=3 R_{\text {on }} I_{c}^{2} \text {, }
$$

where $R_{\text {on }}$ is the equal resistor when switching devices is on and $I_{c}$ is the RMS value of APF compensation current. The real time sampling value is still used for calculation in practical operation.

For the conclusion (2), ignore the APF DC bus voltage fluctuation; the switching loss can be expressed as [20]

$$
p_{s}=\gamma I_{c}
$$

where $\gamma$ is a constant coefficient. The total instantaneous power loss of the equal resistors of the filter inductors is

$$
p_{R}=3 R_{L} I_{c}^{2}
$$


The instantaneous power absorbed by DC bus capacitor can be expressed as

$$
p_{d c}=u_{d c} i_{c}=u_{d c}\left(C \frac{d u_{d c}}{d t}\right) .
$$

The amplitude change of $u_{d c}$ is small and the power fluctuation of capacitor is mainly decided by the change rate of capacitor voltage at steady state. But the amplitude change of $u_{d c}$ is maybe larger when the system is disturbed, so the $u_{d c}$ in (9) still use real time sample value. The instantaneous power of APF absorbed from power grid is expressed by

$$
p_{\text {in }}=p_{R}+Q_{\text {on }}+Q_{s}+p_{d c} .
$$

According to the instantaneous power balance principle, $p_{\text {out }}=p_{\text {in }}$; that is,

$$
3 U \Delta I_{1}=3 R_{\mathrm{eq}} I_{c}^{2}+\gamma u_{d c}+u_{d c}\left(C \frac{d u_{d c}}{d t}\right),
$$

where $R_{\mathrm{eq}}=R_{L}+R_{\mathrm{on}}$.

\section{Variable Structure Controller Design}

3.1. Improved Reaching Law Design. An exponential rate reaching law presented in [22] is as follows:

$$
s_{k+1}=(1-\alpha T) s_{k}-\varepsilon T \operatorname{sgn}\left(s_{k}\right),
$$

where $0<\alpha<1, \varepsilon>0, T$ is the control period and $k$ and $k+1$ denote the present and the next control period, respectively. Let

$$
\operatorname{sgn}\left(s_{k}\right)=\frac{s_{k}}{\left|s_{k}\right|} .
$$

It follows from (12) and (13) that

$$
s_{k+1}=\left[1-\alpha T-\frac{\varepsilon T}{\left|s_{k}\right|}\right] s_{k} .
$$

In order to make the switching function decrease in exponential, that is, the value of switching function $s$ at present control period $T$ less than the last $T$, the following condition should be satisfied:

$$
\left|1-\alpha T-\frac{\varepsilon T}{\left|s_{k}\right|}\right|<1
$$

Soloing (15) gives

$$
\left|s_{k}\right|>\frac{\varepsilon T}{(2-\alpha T)} .
$$

According to (16), we know that the system will decrease in exponential only when the switching function value is relatively big enough. The system becomes the switching control when the condition in (16) is not satisfied. Thus, we can conclude that the sliding mode band of normal exponential reaching law is ribbon and its bandwidth is $\Delta_{1}=$ $\varepsilon T /(2-\alpha T)$. The system will reach a chattering near the sliding mode surface in the process of moving to sliding mode surface in switching band and this will not ensure the system approaches sliding mode surface finally, while the high frequency chattering can excite the high frequency component which is unconsidered when establishing the system model. Thereby, it may increase the burden of controller [23, 24].

A power reaching law presented in [25] is as follows:

$$
s_{k+1}=(1-\alpha T) s_{k}-\beta T\left|s_{k}\right|^{\lambda-1} s_{k} .
$$

It follows from (13) and (17) that

$$
s_{k+1}=(1-\alpha T) s_{k}-\beta T\left|s_{k}\right|^{\lambda} \operatorname{sgn}\left(s_{k}\right),
$$

where $0<\lambda<1, \beta>0$.

This is a variable exponential reaching law actually. The switching control part is big at the beginning and will make the system approach sliding mode surface quickly. But the amplitude of switching control is small when it is near the sliding mode surface. Thus the system could converge to sliding mode surface finally. And the system is stable at the origin. The switching band is sector. This reaching law not only could keep the basic requirements of crossing over switching surface step by step at quasi-sliding mode, but also could effectively inhibit or weaken the chattering.

A piecewise reaching law is proposed to design the variable structure controller for DC bus voltage based on the above two kinds of reaching law:

$$
s_{k+1}= \begin{cases}(1-\alpha T) s_{k}-\varepsilon T \operatorname{sgn}\left(s_{k}\right) & \left|s_{k}\right|>\Delta \\ (1-\alpha T) s_{k}-\beta T\left|s_{k}\right|^{\lambda} \operatorname{sgn}\left(s_{k}\right) & \left|s_{k}\right| \leq \Delta,\end{cases}
$$

where $\Delta$ is the boundary value of sliding mode band selected for the two reaching laws. The quasi-sliding mode band of reaching law in (18) is

$$
\left\{x_{k} \mid\left\|s_{k}\right\|<\Delta_{2}\right\}, \quad \Delta_{2}=\left(\frac{\beta T}{2-\alpha T}\right)^{1 /(1-\lambda)} .
$$

For the reaching law no. 1 in (19), in order to make the sliding mode attenuate in exponential before entering the switching band $\Delta_{1}, \Delta \geq \Delta_{1}$ is needed. Similarly for the reaching law no. 2 , in order to make the sliding mode attenuate in exponential before entering the switching band $\Delta_{2}, \Delta \leq \Delta_{2}$ is needed. Based on the above analysis, we can get $\Delta_{2} \geq \Delta_{1}$.

Taking $\lambda=0.5$ and letting $\Delta_{2}=\Delta=\Delta_{1}$, then

$$
\left(\frac{\beta T}{2-\alpha T}\right)^{2}=\frac{\varepsilon T}{2-\alpha T} .
$$

It can be deduced from (21) that

$$
\beta=\sqrt{\frac{\varepsilon(2-\alpha T)}{T}} .
$$

3.2. Design of APF DC Bus Voltage Variable Structure Controller. Select the error of DC bus voltage and its integration as state variables. Let

$$
x_{1}=\int\left(U_{C}^{*}-u_{d c}\right) d t, \quad x_{2}=\dot{x}_{1}=U_{C}^{*}-u_{d c} .
$$


According to (11), the system state equation can be expressed as

$$
\left[\begin{array}{c}
\dot{x}_{1} \\
\dot{x}_{2}
\end{array}\right]=\left[\begin{array}{ll}
0 & 1 \\
0 & 0
\end{array}\right]\left[\begin{array}{l}
x_{1} \\
x_{2}
\end{array}\right]+\left[\begin{array}{c}
0 \\
\frac{-3 U}{C u_{d c}}
\end{array}\right] \Delta I_{1}+\left[\begin{array}{c}
0 \\
\frac{3 R_{\mathrm{eq}}}{C u_{d c}} I_{c}^{2}+\gamma
\end{array}\right] .
$$

It can be written in matrix form as

$$
\left[\begin{array}{c}
\dot{x}_{1} \\
\dot{x}_{2}
\end{array}\right]=A^{\prime}\left[\begin{array}{l}
x_{1} \\
x_{2}
\end{array}\right]+B^{\prime} \Delta I_{1}+D^{\prime}
$$

where $A^{\prime}, B^{\prime}$ are coefficient matrix and $D^{\prime}$ is disturbance quantity. Discretize (25), one can get that

$$
x_{k+1}=A x_{k}+B \Delta I_{1 k}+D
$$

where $A=I+T A^{\prime}, B=T B^{\prime}, D=T D^{\prime}$, in which $I$ is unit diagonal matrix. Let

$$
s_{k+1}=\left[\begin{array}{ll}
c_{1} & 1
\end{array}\right] x_{k+1}=C x_{k+1}=C\left[A x_{k}+B \Delta I_{1 k}+D\right] .
$$

It follows from (17) and (27) that

$$
\Delta I_{1 k}= \begin{cases}(C B)^{-1}\left[F-\varepsilon T \operatorname{sgn}\left(s_{k}\right)\right] & \left|s_{k}\right|>\frac{\varepsilon T}{(2-\alpha T)}, \\ (C B)^{-1}\left[F-\beta T \sqrt{\left|s_{k}\right|} \operatorname{sgn}\left(s_{k}\right)\right] & \left|s_{k}\right| \leq \frac{\varepsilon T}{(2-\alpha T)},\end{cases}
$$

where $F=-C A x_{k}-C D+(1-\alpha T) s_{k}$.

\section{Simulation and Experiment}

4.1. Simulation. In order to verify the effectiveness of the proposed piecewise reaching law variable structure controller, we establish the simulation model in MATLAB/SIMULINK. The system parameters are as follows: phase voltage is $220 \mathrm{~V}$ (RMS), switching frequency is $10 \mathrm{KHz}, \mathrm{DC}$ bus voltage is $700 \mathrm{~V}$, and filter inductor and capacitor are $5 \mathrm{mH}$ and $4700 \mu \mathrm{F}$, respectively. Three-phase bridge diode rectifier connected with resistor is as the load.

Figures 2 and 3 give the DC bus voltage response wave and the voltage and current wave of power grid phase A when $\mathrm{APF}$ is with nonload operation. From Figure 2, it can be seen that the DC bus voltage rises to the setting value within two sine wave cycles and the response speed is better than that of fuzzy controller. But the overshoot is smaller than that of the PI controller. The voltage fluctuation is very small after stable operation. All these proved that the performance of the proposed variable structure controller is good.

It can be seen from Figure 3 that the charging current of capacitor is big; the reason is that the capacitor voltage is zero at the beginning and the big charging current can make the capacitor voltage rises quickly; then the dynamic response time is shortened. The charging current becomes stable within two sine wave cycles which is consistent with that of the DC bus voltage and is small after stable operation. Its waveform is similar to the sine wave and its phase is almost

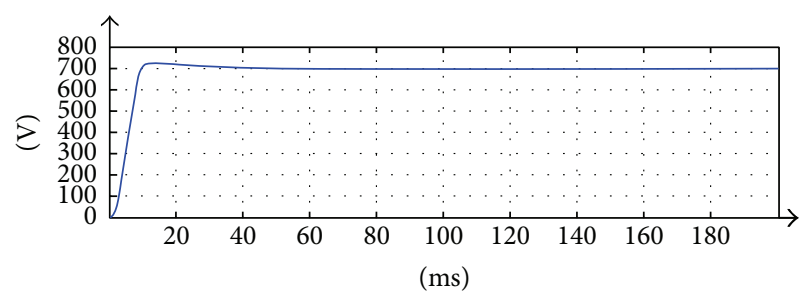

FIGURE 2: Dynamic response curve of DC bus voltage (nonload).

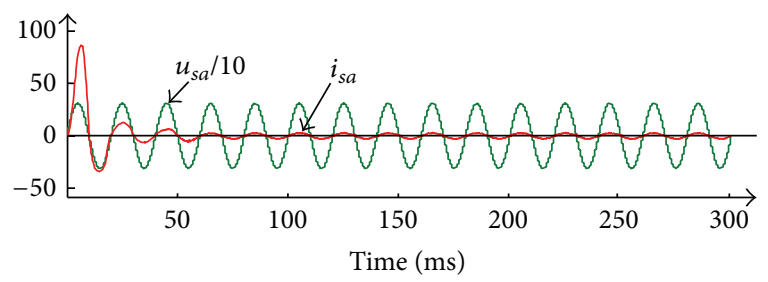

FIGURE 3: Waves of power grid voltage and current.

the same as that of power grid voltage. The active power generation from power grid is used for maintaining the power consumption of APF itself.

In order to verify the dynamic regulation performance of APF DC bus voltage variable structure controller in the event of external disturbance, the simulation research is carried out on the condition that the power grid voltage and load appear fluctuation.

The DC bus voltage and power grid current response curves under the condition that the power grid voltage dumps $10 \%$ and APF operates in stable state with load are given in Figure 4. It can be seen from Figure 4 that the bus voltage droop is little and recovers to the setting value quickly through the regulation of control algorithm. The bus voltage droop caused by the power grid voltage droop increases the charging current of capacitor. At the same time, the load power is decreased and the reason is the same. But the value of load current drop is larger than that of the charging current increment. So the peak current of power grid is decreased from $38.75 \mathrm{~A}$ to $36.25 \mathrm{~A}$. The power grid current transition process is smooth.

Figures 5 and 6 give the DC bus voltage, the power grid voltage, and current response curves when the APF connects with load after power on, in which the load suddenly increases to 2 times of the original at time $150 \mathrm{~ms}$.

It can be seen from Figure 5 that the time of $\mathrm{DC}$ bus voltage getting to the setting value is less than $70 \mathrm{~ms}$. The response time is bigger than that time in Figure 2 because of the current generation from APF including the compensation harmonic and reactive currents. The bus voltage is dropped when the load is suddenly increased at time $150 \mathrm{~ms}$, but it is regulated to setting value by the variable structure controller at about time $220 \mathrm{~ms}$. The droop of bus voltage and the regulation time are larger than that of Figure 4 . The reason is that the value of load increment $(100 \%)$ is larger than the droop (10\%) of power grid voltage. 


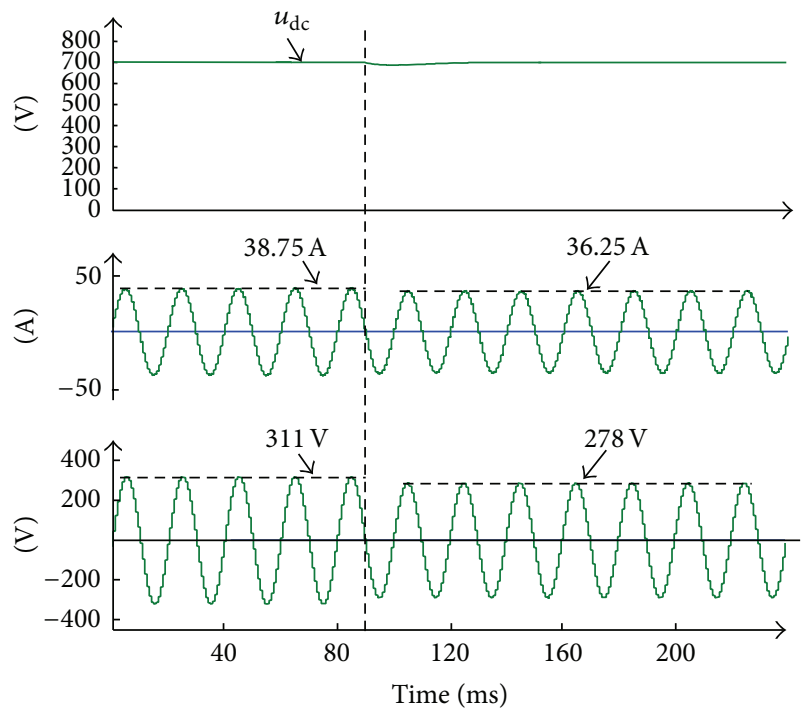

FIGURE 4: Wave of DC bus voltage and power grid current (power grid voltage dumps 10\%).

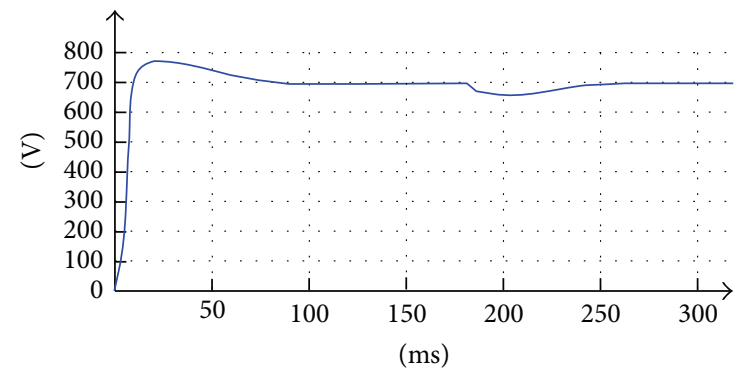

FIGURE 5: Dynamic response wave of DC bus voltage (load changes).

It can be seen from Figure 6 that the phase current tracks the phase voltage well at stable and dynamic operation. The power grid current is sine wave and its phase is almost the same as that of voltage. The transition process is stable and the measured power factor is 0.99 .

From the above simulation results and analysis, we can conclude that the dynamic and static performance of the proposed variable structure controller are excellent. The DC bus voltage is stable and thus ensures the current compensation performance of APF. The problem discussed in the third paragraph of Section 1 is solved well.

4.2. Experiment. In order to verify the effect of the proposed control algorithm, the experiment operates on the existing APF platform. The system uses TMS320F28335 as the control core to execute the control algorithm. The power grid voltage, its frequency, and the filter inductor are $220 \mathrm{~V}$ (RMS), $50 \mathrm{~Hz}$, and $5 \mathrm{mH}$, respectively. As the actual power grid voltage is bigger than $220 \mathrm{~V}$ normally, the DC bus voltage is set as $750 \mathrm{~V}$,

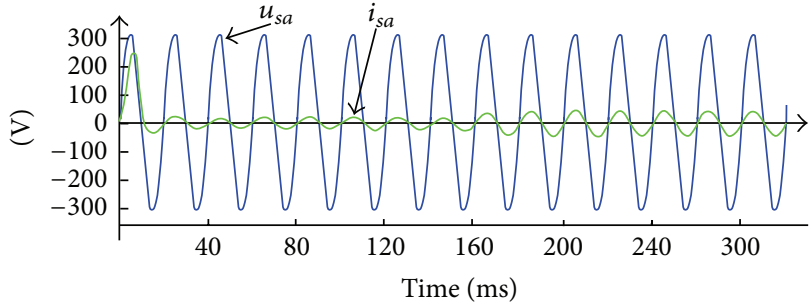

FIGURE 6: Waves of power grid voltage and current (load changes).

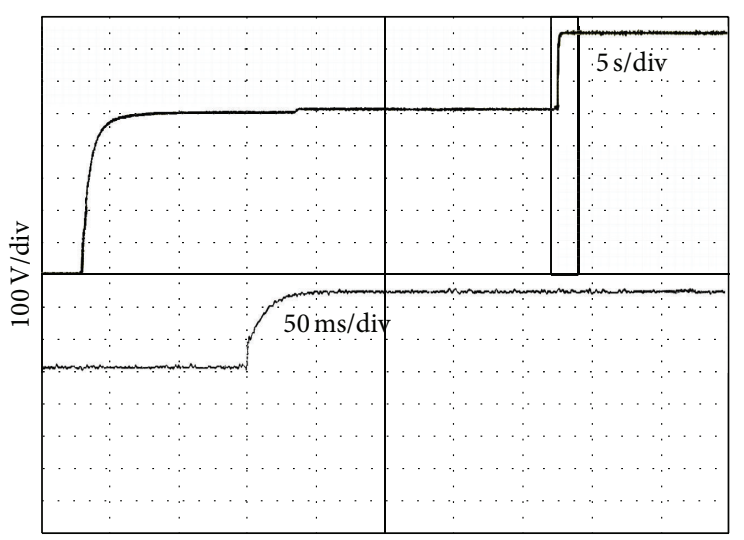

FIGURE 7: DC bus voltage dynamic response curve.

not as $700 \mathrm{~V}$, in simulation. The load is the same as that of simulation. (Figures 7-12 are based on this load.)

The DC bus voltage response curve after power on is given in Figure 7. At the beginning, the power grid charges the capacitor through a $51 \Omega$ current limiting resistor, the APF operated under uncontrolled rectification, and the bus voltage rises rapidly to the stable state. After a certain delay, the $51 \Omega$ resistor is shorted; then the bus voltage rises slightly. Then the PWM boost voltage process is started and the control period is $2 \mathrm{~ms}$. It can be seen from Figure 7 that the time of the DC bus voltage increasing from uncontrolled rectification to the last setting value $750 \mathrm{~V}$ is about $50 \mathrm{~ms}$, the measured actual bus voltage is $745 \mathrm{~V}$, and the fluctuation is $5 \mathrm{~V}$.

Figure 8 gives the wave of power grid voltage and current, in which the APF is with no load and in the stable state. It can be seen that the current is about $2 \mathrm{~A}$ which is consistent with the simulation result. As the bus voltage is stable, the current fluctuation is small. The current rippled around the instruction current in a certain range; the reason is that the current is small and the switching frequency of the power electronic devices is limited. But the current wave outline is similar to sine wave. The phase of current lags that of the voltage. The reason is that there exists reactive power exchanging between the filter inductor and the power grid.

The waves of DC side voltage, load current, power grid current, and the output harmonic current of APF under 


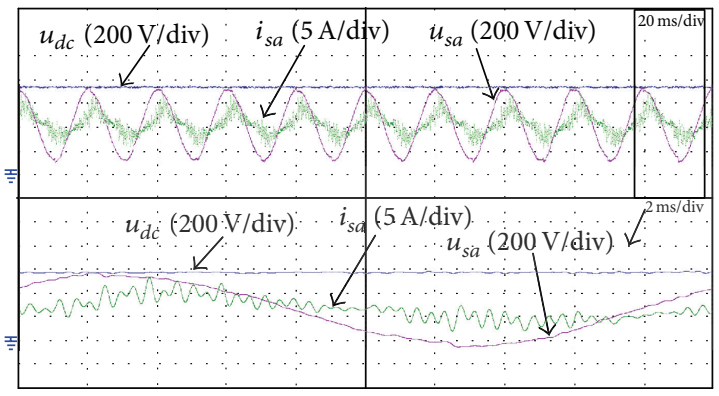

FIGURE 8: APF compensation current (nonload).

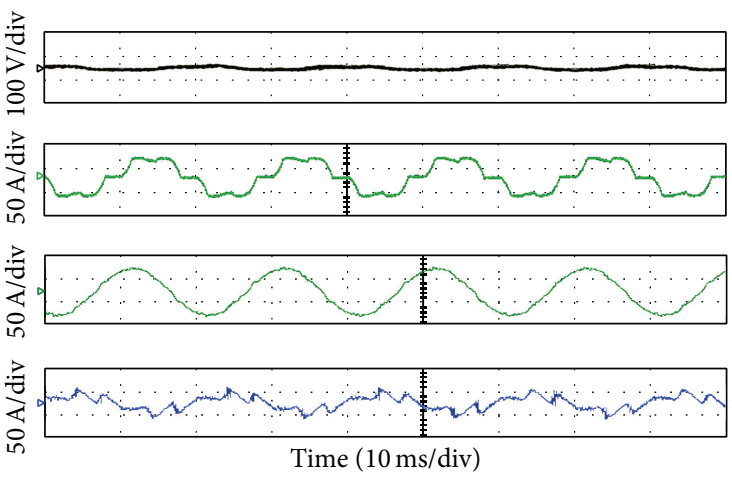

FIGURE 9: Waves of DC bus voltage, load current, power grid current, and APF compensation current.

load operation are given in Figure 9. The measured average DC bus voltage is $740 \mathrm{~V}$ and the fluctuation is $15 \mathrm{~V}$. Its stable error is small. From the current wave it can be seen that the harmonic current components of load current are compensated by APF. The power grid current is sine wave and with no peak burr. The harmonic current from APF had no high frequency component. The experiment result proves that the compensation effect is good.

Figures 10 and 11 give the phase A current spectrum before and after compensation, respectively. It can be seen from Figure 10 that the content of 3rd, 5th, 7th, 9th, 11th, 13 th, and 17th harmonic are big, especially the 5th harmonic. The harmonic component after compensation is very small. The THD value is $26.7 \%$ before compensation and is $6.0 \%$ after compensation. The THD is reduced a lot, and the compensation effect is obvious.

In order to verify the anti-interference performance of the improved reaching law variable structure controller at the event of load disturbance, the load is suddenly increased to 2 times of the original. Figure 12 gives the response waves of DC bus voltage and power grid current. It can be seen from the wave that the variable structure controller can quickly make the system reach a new stable state and the regulation time is no more than $30 \mathrm{~ms}$ and the transition process is smooth.

Figure 13 gives the power grid voltage and current waves after compensation, in which the load is three-phase bridge

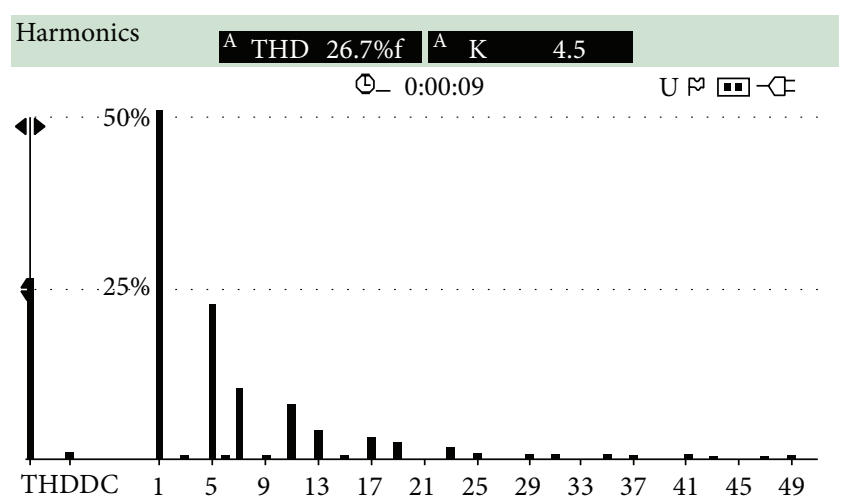

FIgURE 10: Phase A current spectrum before compensation.

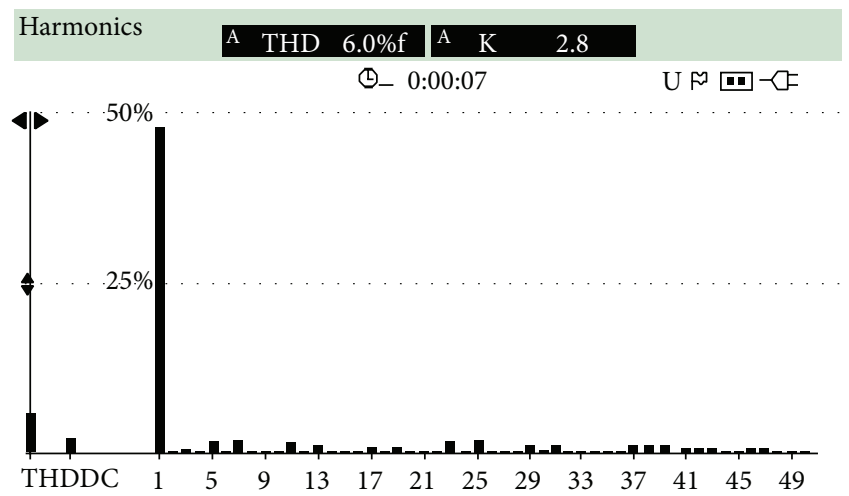

FIgURE 11: Phase A current spectrum after compensation.

diode rectifier connected with resistor-inductor load. It can be seen that the harmonic and reactive currents are also compensated well, the power grid current is sine wave, and its phase is the same as that of the power grid voltage.

\section{Conclusion}

The APF DC bus voltage is very important for APF stable and reliable operation. The DC bus voltage mathematical model has been analyzed and established according to power balance. A DC bus voltage piecewise reaching law variable structure controller has been designed aimed at various disturbances. The simulation and experiment results have proved that the proposed control strategy has some good performances, such as maintaining the DC bus voltage stable, no chattering, insensitiveness to external disturbance, quick dynamic response, and small fluctuation. All of these ensured the steady amplitude, sine wave, little distortion, smooth transition process of the power grid current, and the compensation effect of APF. 


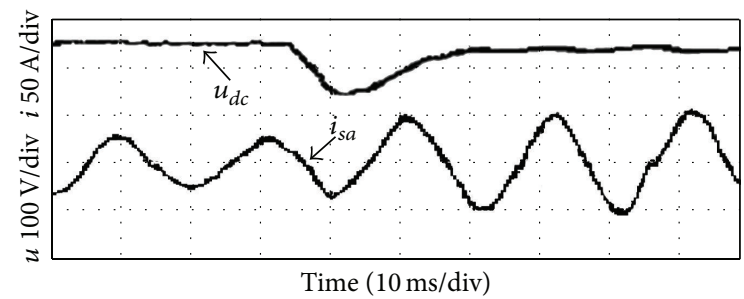

FIGURE 12: Waves of DC bus voltage and power grid current (load changes).

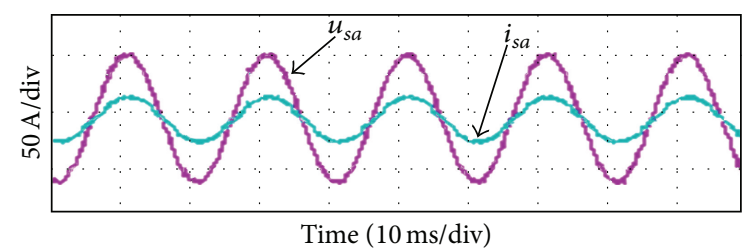

FIGURE 13: Waves of power grid voltage and current after compensation (resistor-inductor load).

\section{Conflict of Interests}

The authors declare that there is no conflict of interests regarding the publication of this paper.

\section{Acknowledgments}

This research has been supported by National Natural Science Foundation of China (61201410), Natural Science Fund for Colleges and Universities in Jiangsu Province (11KJB470002), and Huaian Science and Technology Plan Project (Social Development, HAS2011049). The authors are grateful to the reviewers for their valuable comments.

\section{References}

[1] W. Yong and W. Shuyun, "Reasearch on matlab simulation of harmonic and reactive current detection," Electrical Measurement \& Instrumentation, vol. 42, pp. 21-23, 2005.

[2] S. Yin, X. Li, H. Gao, and O. Kaynak, "Data-based techniques focused on modern industry: an overview," IEEE Transactions on Industrial Electronics, 2014.

[3] Z.-K. Hu, M.-Y. Hu, W.-H. Gui, C.-H. Yang, and Z.-M. He, "Novel self-tuning predictive control method of shunt active power filter," Electric Machines and Control, vol. 14, no. 3, pp. 18-30, 2010.

[4] T. Zhong, J. Yingda, Y. Yongsheng, and W. Guo, "Direct-side voltage control of mid-point capacitor three phase four wire shunt active power filter," Electrical Measurement \& Instrumentation, vol. 48, 41, no. 545, p. 44, 2011.

[5] F. Z. Peng, "Harmonic sources and filtering approaches," IEEE Industry Applications Magazine, vol. 7, no. 4, pp. 18-25, 2001.

[6] S. Yin, S. Ding, X. Xie, and H. Luo, "A review on basic datadriven approaches for industrial process monitoring," IEEE Transactions on Industrial Electronics, vol. 61, no. 11, pp. 64186428, 2014.
[7] A. Chandra, B. Singh, B. N. Singh, and K. Al-Haddad, "An improved control algorithm of shunt active filter for voltage regulation, harmonic elimination, power-factor correction, and balancing of nonlinear loads," IEEE Transactions on Power Electronics, vol. 15, no. 3, pp. 495-507, 2000.

[8] M. Salo and H. Tuusa, "A vector controlled current-source PWM rectifier with a novel current damping method," IEEE Transactions on Power Electronics, vol. 15, no. 3, pp. 464-470, 2000.

[9] P.-F. Chang, J.-L. Zeng, T. Wang, and X.-M. Chen, "Research on DC-side voltage control methods of three-phase four-wire active power filters," Automation of Electric Power Systems, vol. 29, no. 8, pp. 75-78, 2005.

[10] D.-G. Liu, A. Luo, and Z.-K. Shuai, "New issues and solving schemes for controlling the DC-side voltage of new injection type hybrid active power filter," Proceedings of the Chinese Society of Electrical Engineering, vol. 28, no. 30, pp. 27-34, 2008.

[11] C. Yu, L. Huiyun, and L. Qionglin, "An APF design with new DC voltage control strategy," Electrical Applications, vol. 25, no. 7, pp. 79-82, 2006.

[12] F. Bourourou, K. khettab, F. Senani, and S. Guettouche, "Active power filter DC voltage regulation with fuzzy logic controller," in Proceedings of the 4th International Conference on Power Engineering, Energy and Electrical Drives, pp. 87-91, Istanbul, Turkey, May 2013.

[13] L. Zhihua, L. Zhen, and L. Zhenbin, "Self- adaptive fuzzy PI control of DC voltage in active power filter," Chinese Journal of Power Sources, vol. 34, no. 6, pp. 582-585, 2010.

[14] L. Kong, X. Zhang, X. Li, and C. Li, "Research on DC-side voltage fuzzy internal model of shunt active power filter," Transactions of China Electrotechnical Society, vol. 26, no. 1, pp. 224-228, 2011.

[15] M. Hamerlain, T. Youssef, and K. Bouyoucef, "Reducing the chattering using the generalized variable structure control applied to a manipulator arm," in Proceedings of the Canadian Conference on Electrical and Computer Egineering (CCECE '00), vol. 2, pp. 597-604, Halifax, Canada, May 2000.

[16] K. Huang, W. Wang, and X. Wang, "Modeling and simulation of PWM rectifier based on sliding-mode control," Power System Technology, vol. 33, no. 8, pp. 18-23, 2009.

[17] W. Yufeng, S. Bao, and Z. Chengbo, "Application research of adaptive discrete sliding mode control for APF," Electric Drive, vol. 42, 20, no. 8, p. 23, 2012.

[18] S. Yin, X. Yang, and H. R. Karimi, "Data-driven adaptive observer for fault diagnosis," Mathematical Problems in Engineering, vol. 2012, Article ID 832836, 21 pages, 2012.

[19] Z. Ding, B. Liu, and Y. Zhang, "Optimal control for DC side voltage of active power filter based on auto-disturbance rejection control," Power System Technology, vol. 37, no. 7, pp. 2030-2034, 2013.

[20] Z. Dong, L. V. Zhengyu, and C. Guozhu, "Capacitor voltage control of shunt active power filter," Power Electronics, vol. 41, no. 10, pp. 76-79, 2007.

[21] B. Xie, K. Dai, S. Zhang, and Y. Kang, "Optimization control of DC link voltage for shunt active power filter," Proceedings of the Chinese Society of Electrical Engineering, vol. 31, no. 9, pp. 23-29, 2011.

[22] W. Gao, Y. Wang, and A. Homaifa, "Discrete-time variable structure control systems," IEEE Transactions on Industrial Electronics, vol. 42, no. 2, pp. 117-122, 1995. 
[23] O. Xuwen and Y. Huajie, "Sliding mode control research of PMSM based on variable exponential rate reaching law," Micromotors, vol. 44, no. 90, pp. 31-34, 2011.

[24] Y. Mi, W. L. Li, and Y. W. Jing, "Variable structure control for a discrete-time system based on power reaching law," Control and Decision, vol. 23, no. 6, pp. 643-646, 2008.

[25] C. L. Zhai and Z. M. Wu, "A variable structure control method for discrete time systems," Journal of Shanghai Jiaotong University, vol. 34, no. 5, pp. 719-722, 2000. 


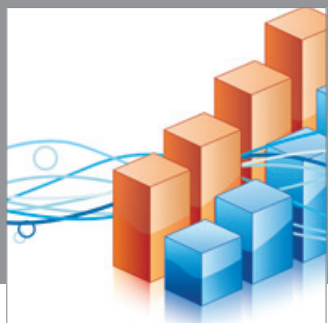

Advances in

Operations Research

mansans

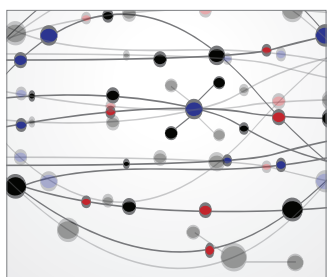

The Scientific World Journal
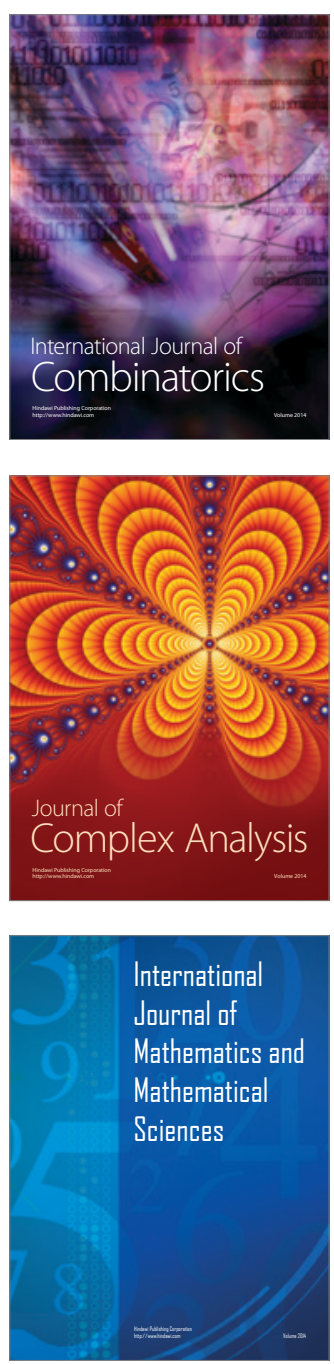
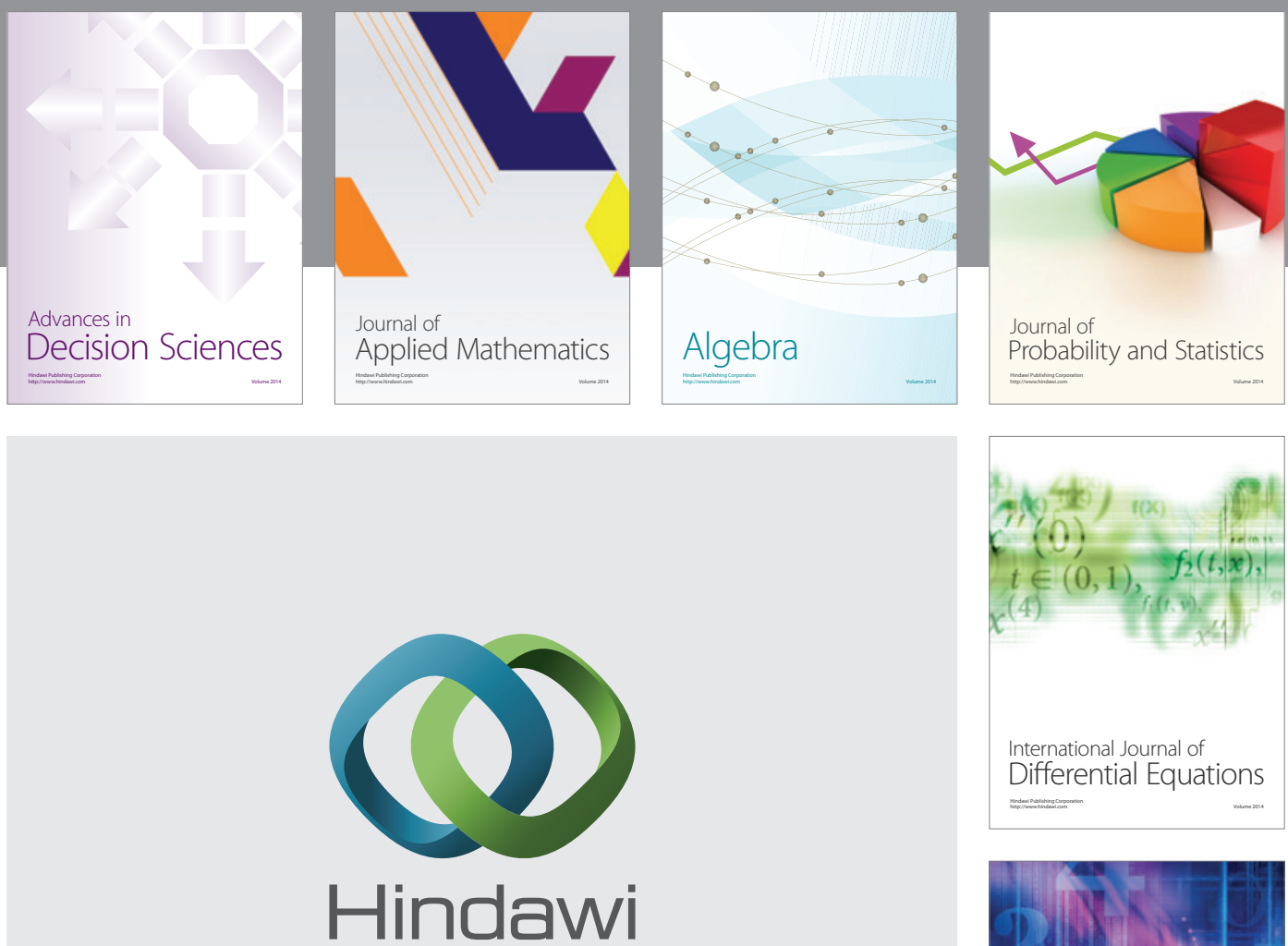

Submit your manuscripts at http://www.hindawi.com
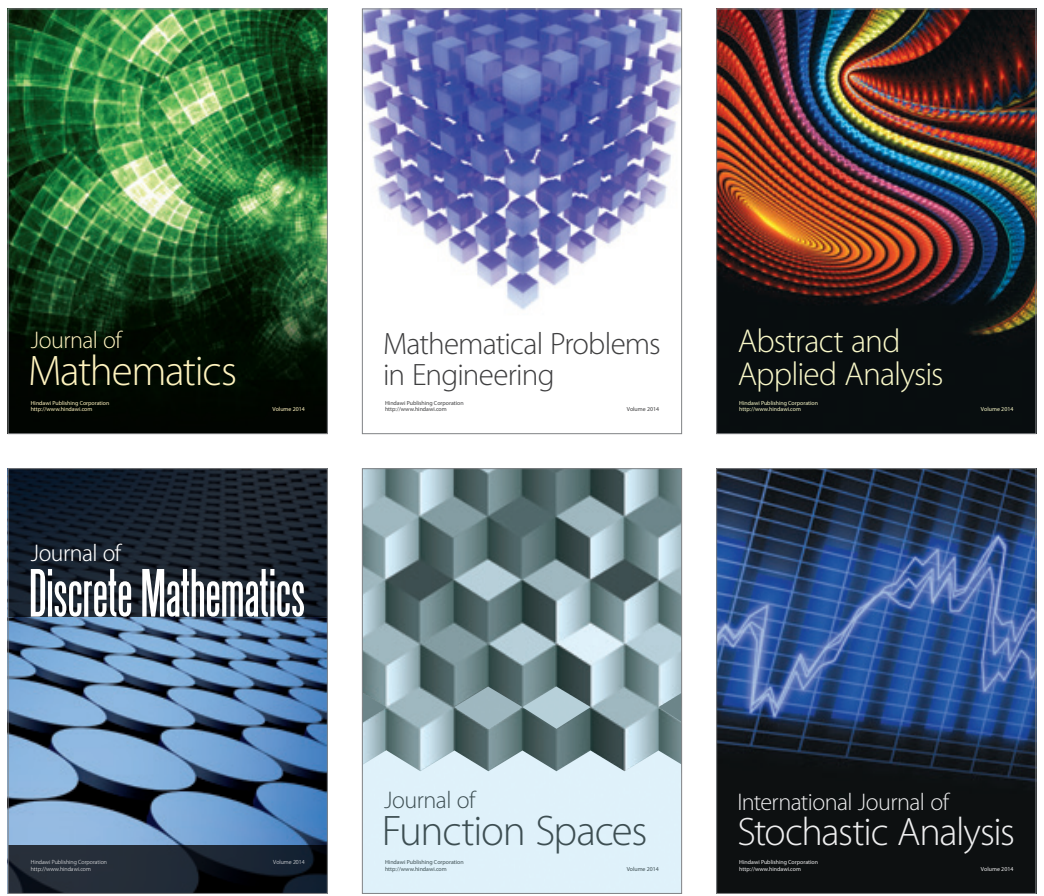

Journal of

Function Spaces

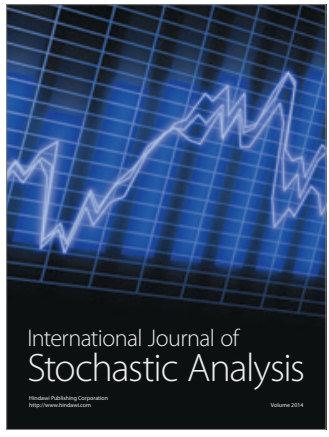

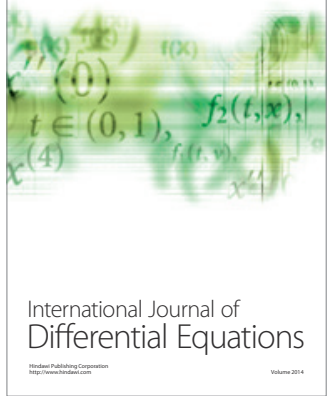
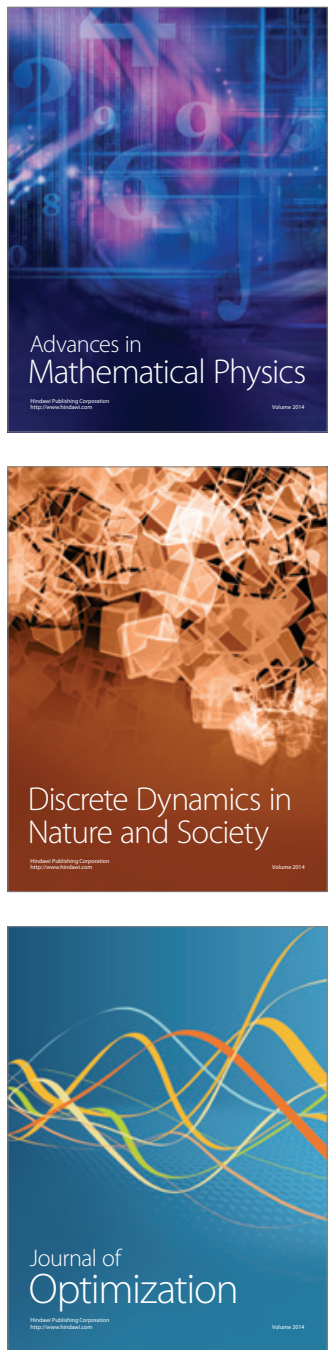